\title{
Viscoelastic Properties of Branched Polymers. II. In Concentrated Solutions
}

\author{
Yoshinobu Isono, Teruo FujIMOTO, ${ }^{\dagger}$ \\ Hirokazu KAJIURA, ${ }^{\dagger \dagger}$ and Mitsuru NAGASAWA \\ Department of Synthetic Chemistry, Nagoya University, \\ Furo-cho, Chikusa-ku, Nagoya 464, Japan.
}

(Received December 28, 1979)

\begin{abstract}
Rheological parameters, i.e., the zero-shear viscosity $\eta^{0}$ and the steady-state compliance $J_{\mathrm{e}}$ of solutions of four-armed, star-shaped and also of highly branched, comb-shaped polystyrenes were determined with a Weissenberg rheogoniometer. The molecular weight and concentration dependences of the parameters of the samples were compared with those of linear polystyrenes and also those of three-armed, star-shaped polymers, published previously. Emphasis is placed on the discussion of the difference between $J_{\mathrm{e}}$ of linear polymers and that of branched polymers.
\end{abstract}

KEY WORDS Star-Shaped Polymer / Comb-Shaped Polymer / Branched Polymer / Zero-Shear Viscosity / Steady-State Compliance / Entanglement /

In a preceding paper, ${ }^{1}$ the viscoelastic behavior of four-armed, star-shaped polymers in the undiluted state was studied in comparison with that of linear polymers. A small but clear difference is observed between the molecular weight dependence of the zero-shear viscosity $\eta^{0}$ of the four-armed polymers and that of linear polymers. ${ }^{2-5}$ Moreover, steadystate compliance $J_{\mathrm{e}}$ of star-shaped polymers was found to be higher than that of linear polymers in the undiluted state, ${ }^{2,4,5}$ in contrast to the behavior in dilute solutions. ${ }^{6,7}$ The differences found between four-armed, star-shaped, and linear polymers are entirely the same as the differences found between highly branched, comb-shaped polymers and linear polymers. ${ }^{8.9}$

In order to understand these phenomena more clearly, rheological parameters, i.e., zero-shear viscosity $\eta^{0}$ and steady-state compliance $J_{\mathrm{e}}$ of solutions of four-armed, star-shaped polystyrenes and also highly branched, comb-shaped polystyrenes at various concentrations were measured

$\dagger$ Present Address: Department of Material Science and Technology, Technological University of Nagaoka, Kamitomioka-cho, Nagaoka, Niigata 949-54, Japan.

${ }^{\dagger \dagger}$ Present Address: Mitsui Petrochemical, Ltd., Waki-cho, Kuga-gun, Yamaguchi 740, Japan. using a Weissenberg rheogoniometer. The data are compared with the corresponding data for linear polystyrenes in solution.

\section{EXPERIMENTAL}

\section{Samples and Solvents}

Four-armed, star-shaped polystyrenes having narrow molecular weight distributions were prepared in a previous work. ${ }^{1}$ The highly branched, comb-shaped polystyrenes were prepared in a previous work ${ }^{8}$ by a coupling reaction between polystyryllithium and chloromethylated polystyrene. Although both the backbone and branches of comb-shaped polystyrenes have sharp molecular weight distributions, the coupling products have distributions with respect to the degree of branching and the samples used in this work were fractionated from the coupling products. Therefore, the samples must have distributions in the number of branches per molecule. The molecular characteristics of the samples used here are listed in Table I. ${ }^{1,8}$

The degree of branching is generally expressed by a parameter $g_{\mathrm{s}}$, which is defined as the ratio of the unperturbed radius of gyration of the branched polymer $\left\langle S_{0}{ }^{2}\right\rangle_{\mathrm{b}}$ to that of the corresponding linear polymer having the same molecular weight $\left\langle S_{0}{ }^{2}\right\rangle_{1}$, 
Table I. Molecular characteristics of the samples

\begin{tabular}{|c|c|c|c|c|c|c|c|c|}
\hline \multirow{2}{*}{ Type } & \multirow{2}{*}{$\begin{array}{l}\text { Sample } \\
\text { code }\end{array}$} & \multicolumn{2}{|c|}{ Molecular weight } & \multirow{2}{*}{$\begin{array}{c}\text { Parent, } \\
M_{n} \times 10^{-4}\end{array}$} & \multirow{2}{*}{$\begin{array}{c}\text { Branch, } \\
M_{n} \times 10^{-5}\end{array}$} & \multirow{2}{*}{$f^{a}$} & \multirow{2}{*}{$g_{\mathrm{s}}(\mathrm{comb})$} & \multirow{2}{*}{$g_{\mathrm{s}}(\mathrm{star})$} \\
\hline & & $M_{w} \times 10^{-6}$ & $M_{n} \times 10^{-6}$ & & & & & \\
\hline \multirow[t]{3}{*}{ Star } & CS-81 & $0.76_{0}$ & $0.75_{0}$ & - & $1.8_{5}$ & 4 & - & 0.625 \\
\hline & CS- 60 & - & $0.48_{8}$ & - & $1.2_{2}$ & 4 & - & 0.625 \\
\hline & CS-25 & - & $0.28_{0}$ & - & $0.71_{5}$ & 4 & - & 0.625 \\
\hline \multirow[t]{11}{*}{ Comb } & $\mathrm{H}-2$ & $8.1_{6}$ & - & $9.7_{6}$ & $1.2_{9}$ & 62.5 & 0.058 & 0.047 \\
\hline & $\mathrm{H}-4$ & $5.3_{3}$ & - & & & 40.5 & 0.088 & 0.072 \\
\hline & H-5 & $3.3_{1}$ & - & & & 24.9 & 0.14 & 0.12 \\
\hline & H-7 & $1.9_{8}$ & - & & & 14.6 & 0.22 & 0.20 \\
\hline & $\mathrm{H}-8$ & $1.4_{0}$ & - & & & $10_{.}$ & 0.31 & 0.28 \\
\hline & I-2 & $6.0_{0}$ & - & $9.7_{6}$ & $1.7_{6}$ & 33.5 & 0.10 & 0.087 \\
\hline & $\mathrm{I}-6$ & $2.4_{4}$ & - & & & 13.3 & 0.24 & 0.22 \\
\hline & $\mathrm{J}-2$ & $4.7_{7}$ & - & $9.7_{6}$ & $3.5_{8}$ & 13.0 & 0.23 & 0.28 \\
\hline & $F-3$ & $3.5_{8}$ & - & $9.5_{0}$ & $0.65_{0}$ & 53.5 & 0.079 & 0.057 \\
\hline & F-6 & $1.1_{6}$ & - & & & 16.3 & 0.23 & 0.18 \\
\hline & $F-12$ & $0.48_{8}$ & - & & & 6.0 & 0.47 & 0.44 \\
\hline \multirow[t]{2}{*}{ Linear } & L-201 & $1.4_{0}$ & - & - & - & - & - & - \\
\hline & L-80 & $0.82_{2}$ & - & - & - & - & - & - \\
\hline
\end{tabular}

a $f$ is the number of branches per molecule.

such as

$$
g_{\mathrm{s}} \equiv\left\langle S_{0}{ }^{2}\right\rangle_{\mathrm{b}} /\left\langle S_{0}{ }^{2}\right\rangle_{1}
$$

The $g_{\mathrm{s}}$ is related to the number of branches per molecule $f$ by ${ }^{10-12}$

$$
\begin{gathered}
g_{\mathrm{s}}(\mathrm{star})=(3 f-2) / f^{2} \\
g_{\mathrm{s}}(\mathrm{comb})=(1+f \gamma)^{-3} \\
\left\{1+2 f \gamma+\left(2 f+f^{2}\right) \gamma^{2}+\left(3 f^{2}-2 f\right) \gamma^{3}\right\}
\end{gathered}
$$

where $\gamma$ is the ratio of the molecular weight of a branch to that of the backbone. The values of $g_{\mathrm{s}}$ of the present samples calculated from eq 2 and 3 are listed in Table I. Since the values of $g_{\mathrm{s}}$ of the combshaped polymers calculated as star (i.e., from eq 2) show reasonable agreement with $g_{\mathrm{s}}$ calculated as comb (i.e., from eq 3 ), the comb-shaped polymers used in this work may well be regarded as starshaped polymers in this sense. This is because the molecular weight of the branches of comb-shaped polymers is high compared with the molecular weight of the backbone.

Linear polymers having narrow molecular weight distributions and used for comparison were also prepared in our laboratory. ${ }^{13}$

The $\alpha$-chloronaphthalene $(\alpha-\mathrm{CN})$ of the special grade of Katayama Chemical Co. was purified by recrystallization from a hexane solution at -30 to $-40^{\circ} \mathrm{C}$ and then by distillation under $10^{-4} \mathrm{mmHg}$ at about $120^{\circ} \mathrm{C}$. The density and viscosity of $\alpha-\mathrm{CN}$ were $1.168 \mathrm{~g} \mathrm{ml}^{-1}$ and $1.65 \mathrm{cP}$, at $50^{\circ} \mathrm{C}$, respectively. Dioctyl phthalate (DOP) was used as a $\theta$-solvent $\left(22^{\circ} \mathrm{C}\right.$ is the $\theta$-temperature $\left.{ }^{14}\right)$. The purification of DOP was carried out by distillation under $10^{-4}$ $\mathrm{mmHg}$ at about $180^{\circ} \mathrm{C}$. The density and viscosity of DOP were $0.9767 \mathrm{~g} \mathrm{ml}^{-1}$ and $47.2 \mathrm{cP}$, at $30^{\circ} \mathrm{C}$, respectively.

\section{Measurements}

Measurements of the primary normal stress difference and shear stress were carried out with a Weissenberg rheogoniometer, type R-17, manufactured by Sangamo Controls Ltd., and equipped with a gap-servo system. The details and reliability of the Weissenberg rheogoniometer, type $\mathrm{R}-17$, in the present experimental range, were reported pre- 
viously. ${ }^{15,16}$ The cone and plate had a $5 \mathrm{~cm}$ diameter and $4^{\circ}$ angle. The experiments with four-armed and comb-shaped polymers were carried out at $50^{\circ} \mathrm{C}$ and $30^{\circ} \mathrm{C}$, respectively, with an accuracy of $\pm 0.1^{\circ} \mathrm{C}$.

Solutions of about $(30-40) \mathrm{g} \mathrm{dl}^{-1}$ in $\alpha-\mathrm{CN}$ and about $16 \mathrm{~g} \mathrm{dl}^{-1}$ in DOP were first prepared by mixing weighed amounts of the polymer and solvent at about $50^{\circ} \mathrm{C}$. To accelerate the dissolution of the polymer, a considerable amount of cyclohexane was added to the mixtures. The mixtures were gently stirred three times a day by hand until they became uniform. Cyclohexane was removed by evaporation in a vacuum oven at $50^{\circ} \mathrm{C}$. Dilution was carried out on a weight basis. Polymer concentrations were converted to $\mathrm{g} \mathrm{dl}^{-1}$, assuming the additivity of specific volumes of polymer and solvent.

\section{RESULTS}

The viscosity coefficient $\eta(\dot{\gamma})$ and the primary normal stress difference coefficient $\Psi_{12}(\gamma)$ are calculated as $P_{12} / \dot{\gamma}$ and $\left(P_{11}-P_{22}\right) / \dot{\gamma}^{2}$, respectively, where $P_{12}$ is the shear stress, $\left(P_{11}-P_{22}\right)$ is the primary normal stress difference, measured with the Weissenberg rheogoniometer, and $\dot{\gamma}$ is the shear rate. The zero-shear viscosity $\eta^{0}$ and the zero-shear primary normal stress difference coefficient $\Psi_{12}^{0}$

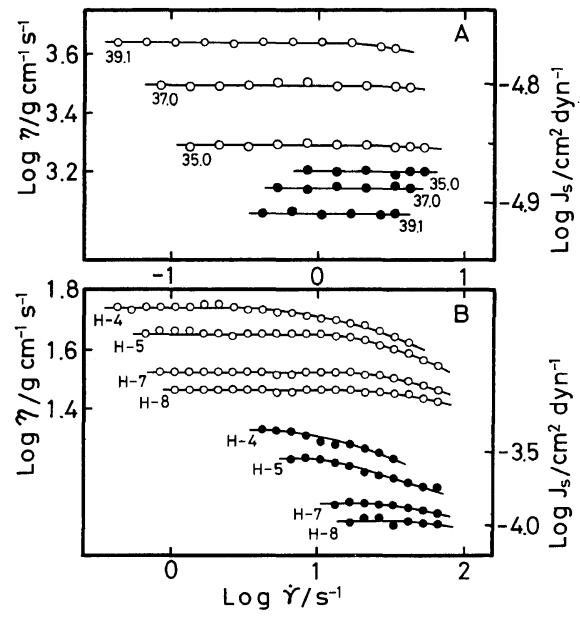

Figure 1. Examples of double-logarithmic plot of $\eta(\dot{\gamma})$ (O) and $J_{\mathrm{s}}(\dot{\gamma})(\bigcirc) v s . \dot{\gamma}$. (A) Sample is four-armed, starshaped polystyrene $\mathrm{CS}-81$ in $\alpha-\mathrm{CN}$ at $50^{\circ} \mathrm{C}$. Concentrations $\left(\mathrm{g} \mathrm{dl}^{-1}\right)$ are shown in the figure. (B) Samples are highly branched, comb-shaped polystyrenes in DOP at $30^{\circ} \mathrm{C}$. Concentrations are all about $8 \mathrm{~g} \mathrm{dl}^{-1}$. Sample codes are shown in the figure. were determined by extrapolation to the zero-shear rate. The steady-state compliance $J_{\mathrm{e}}$ can be determined by extrapolating the apparant steady-state compliance $J_{\mathrm{s}}$, calculated from eq 4 , to the zeroshear rate.

$$
J_{\mathrm{s}}=\left(P_{11}-P_{22}\right) / 2 P_{12}^{2}
$$

Examples of $\log \eta(\dot{\gamma})$ and $\log J_{\mathrm{s}}(\dot{\gamma}) v s . \log \dot{\gamma}$ plots of $\alpha$-CN solutions of four-armed, star-shaped polystyrene CS-81 at various concentrations are shown in Figure 1(A). In the case of star-shaped polymers which have sharp molecular weight distributions, the steady-state compliance $J_{\mathrm{e}}$ can be safely determined by extrapolating $J_{\mathrm{s}}$ to the zero-shear rate. In the case of comb-shaped polymers which have distributions with respect to the degree of branching, however, it was possible to determine $J_{\mathrm{e}}$ only for a limited number of samples because of the high shear rate dependence of $J_{\mathrm{s}}$. Examples of $\log \eta(\gamma)$ and $\log J_{\mathrm{s}}(\dot{\gamma})$ vs. $\log \dot{\gamma}$ plots of DOP solutions of comb-shaped polystyrenes are shown in Figure 1(B). All data of the zero-shear viscosity $\eta^{0}$ and the steady-state compliance $J_{\mathrm{e}}$ of the present samples are listed in Table II.

The $\log \eta^{0} v s . \log C$ curves for $\alpha-\mathrm{CN}$ solutions of linear and star-shaped polystyrenes and those for DOP solutions of linear and comb-shaped polystyrenes are shown in Figures 2 and 3, respectively. It can be pointed out in both figures that the curves of branched polymers are parallel to those of linear polymers irrespective of molecular weight and degree of branching. The $\log \eta^{0} v s . \log M$ curves for $\alpha-\mathrm{CN}$ solutions of star-shaped polystyrenes are shown in comparison with those for linear polystyrenes in Figure 4. The slope in $\log \eta^{0}$ vs. $\log M$ curves of linear polymers is believed to be $3.4,{ }^{4,5}$ though the present experimental points are only two. From the figure, it is certain that the slopes of star-shaped polystyrenes are higher than 3.4 in a higher molecular weight range. This conclusion is the same as that obtained for various branched polymers in previous works. ${ }^{8,9,17-24}$ That is, the zero-shear viscosities of star-shaped and combshaped polymers are lower than those of linear polymers having the same molecular weights and reveal concentration dependences similar to those of linear polymers, as predicted from the theories. $^{2,25-27}$ However, the molecular weight dependence of $\eta^{0}$ of the branched polymers is steeper than that of linear polymers. 
Y. Isono, T. Fujimoto, H. KajIURA, and M. NaGASAWA

Table II. Steady flow viscosity and compliance at zero shear rate

\begin{tabular}{|c|c|c|c|c|c|}
\hline \multirow{2}{*}{ Sample } & \multirow{2}{*}{ Solvent } & \multirow{2}{*}{$\frac{\text { Temp }}{{ }^{\circ} \mathrm{C}}$} & \multirow{2}{*}{$\frac{C}{\mathrm{~g} \mathrm{dl}^{-1}}$} & \multirow{2}{*}{$\frac{\eta^{0}}{\text { Poise }}$} & \multirow{2}{*}{$\frac{J_{\mathrm{e}}}{\mathrm{cm}^{2} \mathrm{dyn}^{-1}}$} \\
\hline & & & & & \\
\hline \multirow[t]{12}{*}{ CS-81 } & $\alpha-\mathrm{CN}$ & $50.0 \pm 0.1$ & 39.1 & $4.37 \times 10^{3}$ & $1.22 \times 10^{-5}$ \\
\hline & & & 37.0 & $3.13 \times 10^{3}$ & $1.28 \times 10^{-5}$ \\
\hline & & & 35.0 & $1.96 \times 10^{3}$ & $1.34 \times 10^{-5}$ \\
\hline & & & 32.8 & $1.26 \times 10^{3}$ & $1.40 \times 10^{-5}$ \\
\hline & & & 29.0 & $6.06 \times 10^{2}$ & $1.56 \times 10^{-5}$ \\
\hline & & & 25.8 & $2.66 \times 10^{2}$ & $1.83 \times 10^{-5}$ \\
\hline & & & 21.8 & $9.72 \times 10^{1}$ & $2.27 \times 10^{-5}$ \\
\hline & & & 18.1 & $3.86 \times 10^{1}$ & $2.71 \times 10^{-5}$ \\
\hline & & & 14.9 & $1.61 \times 10^{1}$ & $3.22 \times 10^{-5}$ \\
\hline & & & 11.6 & $5.88 \times 10^{0}$ & - \\
\hline & & & 8.07 & $1.85 \times 10^{0}$ & - \\
\hline & & & 5.76 & $7.87 \times 10^{-1}$ & - \\
\hline \multirow[t]{6}{*}{ CS-60 } & $\alpha-\mathrm{CN}$ & $50.0 \pm 0.1$ & 48.8 & $4.16 \times 10^{3}$ & $6.14 \times 10^{-6}$ \\
\hline & & & 39.1 & $7.48 \times 10^{2}$ & $7.71 \times 10^{-6}$ \\
\hline & & & 31.5 & $1.28 \times 10^{2}$ & $9.45 \times 10^{-6}$ \\
\hline & & & 25.1 & $3.76 \times 10^{1}$ & - \\
\hline & & & 20.0 & $1.37 \times 10^{1}$ & - \\
\hline & & & 14.0 & $3.66 \times 10^{0}$ & - \\
\hline \multirow[t]{4}{*}{ CS-25 } & $\alpha-\mathrm{CN}$ & $50.0 \pm 0.1$ & 39.4 & $1.77 \times 10^{2}$ & - \\
\hline & & & 31.3 & $4.67 \times 10^{1}$ & - \\
\hline & & & 25.0 & $1.47 \times 10^{1}$ & - \\
\hline & & & 17.8 & $3.76 \times 10^{0}$ & - \\
\hline \multirow[t]{5}{*}{$\mathrm{H}-2$} & DOP & $30.0 \pm 0.1$ & 15.9 & $2.53 \times 10^{3}$ & $8.74 \times 10^{-4}$ \\
\hline & & & 11.8 & $4.58 \times 10^{2}$ & - \\
\hline & & & 7.85 & $7.97 \times 10^{1}$ & - \\
\hline & & & 5.82 & $2.40 \times 10^{1}$ & $9.60 \times 10^{-4}$ \\
\hline & & & 2.92 & $3.14 \times 10^{0}$ & - \\
\hline \multirow[t]{5}{*}{$\mathrm{H}-4$} & DOP & $30.0 \pm 0.1$ & 15.9 & $1.55 \times 10^{3}$ & $4.01 \times 10^{-4}$ \\
\hline & & & 11.9 & $3.38 \times 10^{2}$ & - \\
\hline & & & 7.86 & $5.50 \times 10^{1}$ & $4.33 \times 10^{-4}$ \\
\hline & & & 5.86 & $1.84 \times 10^{1}$ & $4.65 \times 10^{-4}$ \\
\hline & & & 2.80 & $2.36 \times 10^{0}$ & - \\
\hline \multirow[t]{5}{*}{ H-5 } & DOP & $30.0 \pm 0.1$ & 15.9 & $1.22 \times 10^{3}$ & $1.97 \times 10^{-4}$ \\
\hline & & & 11.8 & $2.74 \times 10^{2}$ & - \\
\hline & & & 7.85 & $4.50 \times 10^{1}$ & $2.80 \times 10^{-4}$ \\
\hline & & & 5.91 & $1.59 \times 10^{1}$ & $3.14 \times 10^{-4}$ \\
\hline & & & 2.95 & $2.25 \times 10^{0}$ & - \\
\hline \multirow[t]{3}{*}{$\mathrm{H}-7$} & DOP & $30.0 \pm 0.1$ & 11.8 & $1.85 \times 10^{2}$ & - \\
\hline & & & 7.82 & $3.28 \times 10^{1}$ & $1.40 \times 10^{-4}$ \\
\hline & & & 5.85 & $1.17 \times 10^{1}$ & - \\
\hline
\end{tabular}


Viscoelastic Properties of Branched Polymers. II.

\begin{tabular}{|c|c|c|c|c|c|}
\hline $\mathrm{H}-8$ & DOP & $30.0 \pm 0.1$ & $\begin{array}{l}15.9 \\
11.8 \\
7.87 \\
5.85\end{array}$ & $\begin{array}{l}6.55 \times 10^{2} \\
1.49 \times 10^{2} \\
2.86 \times 10^{1} \\
9.33 \times 10^{-1}\end{array}$ & $\begin{array}{c}- \\
- \\
1.05 \times 10^{-4} \\
-\end{array}$ \\
\hline $\mathrm{I}-2$ & DOP & $30.0 \pm 0.1$ & 11.9 & $7.34 \times 10^{2}$ & $7.21 \times 10^{-4}$ \\
\hline I-6 & DOP & $30.0 \pm 0.1$ & 11.9 & $3.27 \times 10^{2}$ & $1.48 \times 10^{-4}$ \\
\hline $\mathrm{J}-2$ & DOP & $30.0 \pm 0.1$ & 11.9 & $3.10 \times 10^{3}$ & $3.06 \times 10^{-4}$ \\
\hline L-201 & $\alpha-\mathrm{CN}$ & $50.0 \pm 0.1$ & $\begin{array}{c}23.4 \\
20.0 \\
17.1 \\
14.2 \\
11.8 \\
9.26 \\
7.30 \\
5.11\end{array}$ & $\begin{array}{l}1.26 \times 10^{4} \\
4.75 \times 10^{4} \\
1.93 \times 10^{4} \\
7.76 \times 10^{2} \\
2.94 \times 10^{2} \\
8.98 \times 10^{1} \\
3.38 \times 10^{1} \\
8.18 \times 10^{0}\end{array}$ & $\begin{array}{l}3.31 \times 10^{-5} \\
4.57 \times 10^{-5} \\
6.31 \times 10^{-5} \\
8.50 \times 10^{-5} \\
1.38 \times 10^{-4} \\
2.14 \times 10^{-4} \\
2.86 \times 10^{-4} \\
3.75 \times 10^{-4}\end{array}$ \\
\hline L-80 & $\alpha-\mathrm{CN}$ & $50.0 \pm 0.1$ & $\begin{array}{c}31.2 \\
27.7 \\
24.1 \\
20.0 \\
15.9 \\
12.7 \\
10.0 \\
7.12\end{array}$ & $\begin{array}{l}1.22 \times 10^{4} \\
5.76 \times 10^{3} \\
2.51 \times 10^{3} \\
7.72 \times 10^{2} \\
2.54 \times 10^{2} \\
7.45 \times 10^{1} \\
2.80 \times 10^{1} \\
7.47 \times 10^{0}\end{array}$ & $\begin{array}{c}1.86 \times 10^{-5} \\
2.34 \times 10^{-5} \\
3.09 \times 10^{-5} \\
4.47 \times 10^{-5} \\
6.20 \times 10^{-5} \\
1.06 \times 10^{-4} \\
1.30 \times 10^{-4} \\
-\end{array}$ \\
\hline & DOP & $30.0 \pm 0.1$ & $\begin{array}{c}15.9 \\
11.9 \\
7.84 \\
5.95\end{array}$ & $\begin{array}{l}8.00 \times 10^{3} \\
1.56 \times 10^{3} \\
1.70 \times 10^{2} \\
4.90 \times 10^{1}\end{array}$ & $\begin{array}{l}9.14 \times 10^{-5} \\
1.45 \times 10^{-4} \\
2.56 \times 10^{-4} \\
3.02 \times 10^{-4}\end{array}$ \\
\hline
\end{tabular}

The polymer concentration and molecular weight dependences of the steady-state compliance $J_{\mathrm{e}}$ of linear polymers has been studied carefully by various authors. ${ }^{3-5}$ If the concentration or the molecular weight is high enough so that the polymer molecules form a quasi-network, $J_{\mathrm{e}}$ is proportional to the inverse square of the polymer concentration $C$ and independent of the molecular weight $M$; but, if the concentration or the molecular weight is below a critical one, $J_{\mathrm{e}}$ becomes proportional to $M / C$, according to the theories of Rouse,${ }^{28}$ Bueche, ${ }^{29}$ and Zimm. ${ }^{40}$ That is,

$$
J_{\mathrm{e}} / M^{2} \propto(C M)^{\alpha}
$$

where the constant $\alpha$ is -2 and -1 in the former (the network region) and in latter (the Rouse region) regions, respectively. The transition from the Rouse region to the network region is sharp if the molecular weight distribution of the sample is sharp. ${ }^{3}$

The plots of $\log J_{\mathrm{e}}$ of linear polystyrene in $\alpha-\mathrm{CN}$ (good solvent) and in DOP ( $\theta$-solvent) vs. $\log C$ are shown in Figure 5. The data of $J_{\mathrm{e}}$ in DOP were obtained at $30^{\circ} \mathrm{C}$ and converted to the data at $50^{\circ} \mathrm{C}$ by multiplying $(273+30) \rho /(273+50) \rho_{0}$, where $\rho$ and $\rho_{0}$ are the densities at $30^{\circ} \mathrm{C}$ and $50^{\circ} \mathrm{C}$, respectively. It can be pointed out that $J_{\mathrm{e}}$ in both solvents coincide with each other in the network region but are different in the Rouse region. $J_{\mathrm{e}}$ in DOP $(\theta$-solvent) is higher than that in $\alpha$-CN (good solvent) in the Rouse region. The fact that $J_{\mathrm{e}}$ in $\theta$ solvents is higher than that in good solvents was reported for poly $(\alpha$-methylstyrene)s in a previous paper. ${ }^{25}$

The concentration dependence of $J_{\mathrm{e}}$ of fourarmed polystyrenes in $\alpha-\mathrm{CN}$ is also shown in Figure 


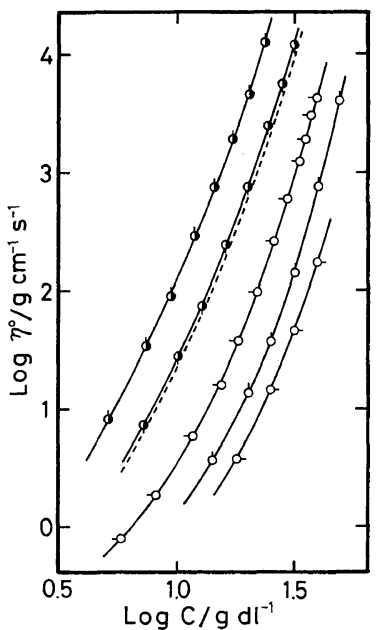

Figure 2. Polymer concentration dependence of $\eta^{0}$. The symbols $\bigcirc$ with pip-left, up and right show the data for $\alpha-C N$ solutions of four-armed, star-shaped polystyrenes CS-81, CS-60, and CS- 25 at $50^{\circ} \mathrm{C}$, respectively. Other symbols with pip-up and down show the data for $\alpha-C N$ solutions of linear polystyrenes L-201 and L-80 at $50^{\circ} \mathrm{C}$, respectively. The broken line shows the values of $\eta^{0}$ for linear polymers with the same molecular weight as four-armed polymer CS-81, which were estimated by extrapolation of the obtained values for other linear polystyrenes.

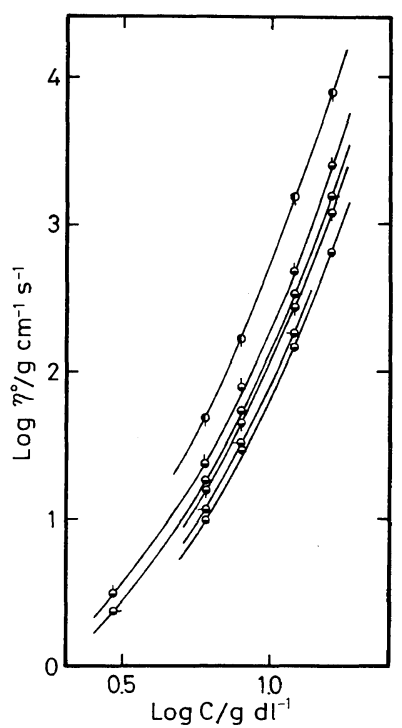

Figure 3. Polymer concentration dependence of $\eta^{0}$. The symbols $\ominus$ with pip-up, right, down, left, and with no-pip show the data of DOP solutions of comb-shaped polystyrenes $\mathrm{H}-2, \mathrm{H}-4, \mathrm{H}-5, \mathrm{H}-7$, and $\mathrm{H}-8$ at $30^{\circ} \mathrm{C}$, respectively. Other symbol with pip-down shows the data for DOP solutions of linear polystyrene L-80 at $30^{\circ} \mathrm{C}$.

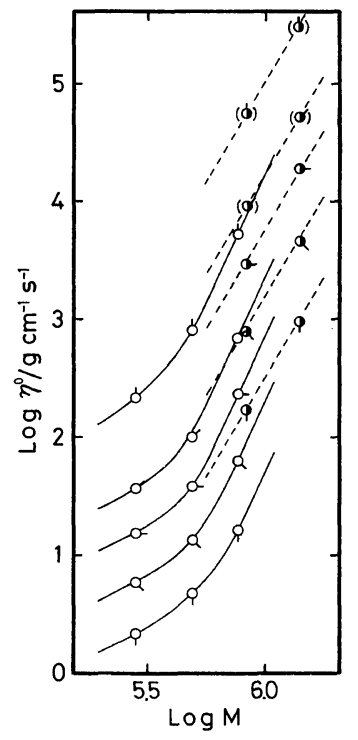

Figure 4. Molecular weight dependence of $\eta^{0}$ at various polymer concentrations. Symbols $\bigcirc$ and $\bigcirc$ show the data for $\alpha-\mathrm{CN}$ solutions of four-armed, star-shaped, and linear polystyrenes at $50^{\circ} \mathrm{C}$, respectively. Various directions of pips show concentrations; succesive $45^{\circ}$ rotations clockwise from the upward direction correspond to $40,30,25,20$, and $15 \mathrm{~g} \mathrm{dl}^{-1}$, respectively. Parentheses denote the estimated values by extraporation of the experimental curves in Figure 2.

5. The double circles show the data of $J_{\mathrm{e}}$ in the undiluted state, which were reduced from the values at $140^{\circ} \mathrm{C}^{1}$ to the values at $50^{\circ} \mathrm{C}$ by multiplying $(273+140) \rho /(273+50) \rho_{0}$, where $\rho$ and $\rho_{0}$ are the densities at $140^{\circ} \mathrm{C}$ and $50^{\circ} \mathrm{C}$, respectively. The values of $J_{\mathrm{e}}$ determined by the stress-relaxation method agree with the extrapolated values of the Weissenberg rheogoniometer data, as was already reported for linear polymers. ${ }^{3}$

In the Rouse region, $J_{\mathrm{e}}$ of four-armed polystyrenes is lower than, and parallel to that of the corresponding linear polystyrenes, as in the case of three-armes poly $(\alpha$-methylstyrene $){ }^{25}$ However, a network region could not be found with fourarmed, star-shaped polystyrenes in the present experimental range. The linear relationship between $J_{\mathrm{e}}$ and $1 / C$ is extended beyond the line for the network region of linear polymers.

$J_{\mathrm{e}}$ of DOP solutions of comb-shaped polystyrenes at various concentrations will be plotted in a 
Viscoelastic Properties of Branched Polymers. II.

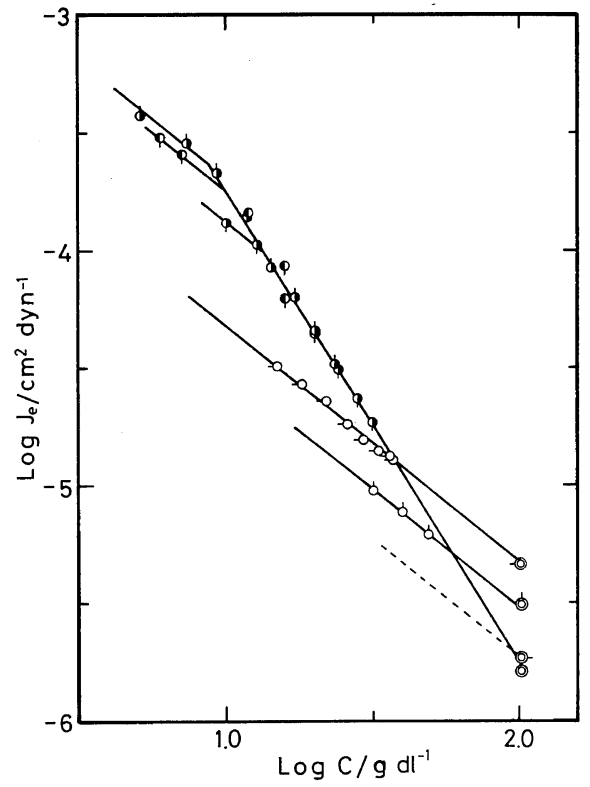

Figure 5. Polymer concentration dependence of $J_{\mathrm{e}}$. Temperature $50^{\circ} \mathrm{C}$. Symbols $\odot$ with pip-left, up and right show the data for four-armed, star-shaped polystyrenes CS-81, CS-60, and CS-25 at the undiluted state, respectively, determined from the relaxation master curves, reported previously. ${ }^{1}$ Symbol $\odot$ without pip shows the data for undiluted linear polystyrene with $M_{w}=3.68 \times 10^{5}$, reported previously. ${ }^{9}$ Other symbols are the same as in Figures 2 and 3. All data of $J_{\mathrm{e}}$ at temperatures other than $50^{\circ} \mathrm{C}$ were reduced to the values at $50^{\circ} \mathrm{C}$ by multiplying $(273+T) \rho /(273+50) \rho_{0}$, where $\rho$ and $\rho_{0}$ were the densities at the temperature of measurement $T$ and $50^{\circ} \mathrm{C}$, respectively.

different way in the discussion section (Figures 6 and 7).

\section{DISCUSSION}

\section{Steady-State Compliance}

It is convenient for further discussion to use the reduced steady-state compliance $J_{\text {eR }}$ defined by

$$
J_{\mathrm{eR}}=\frac{J_{\mathrm{e}} C R T}{M}\left(\frac{\eta^{0}}{\eta^{0}-\eta_{\mathrm{s}}}\right)^{2}
$$

where $\eta^{0}$ and $\eta_{\mathrm{s}}$ are the zero-shear viscosities of solution and solvent, respectively. Equation 5 is then transformed into

$$
J_{\mathrm{eR}} \propto(C M)^{\beta}
$$

and $\beta=-1$ and 0 in the network region and Rouse region, respectively.

$J_{\mathrm{eR}}$ of DOP solutions of comb-shaped polystyrenes is double-logarithmically plotted against $C M$ in Figure 6(A), while the same plots for fourarmed, star-shaped, and linear polystyrenes in solutions and also in the undiluted state ${ }^{1}$ are shown in Figure 6(B). It was previously reported that $J_{\mathrm{e}}$ of comb-shaped polystyrenes in the undiluted state is independent of the molecular weight and much larger than that of the corresponding linear polymers. ${ }^{8}$ The data of comb-shaped polystyrenes in the undiluted state are re-plotted in the present form in Figure 6(A). When we observe $J_{\mathrm{e}}$ of comb-shaped polystyrenes in the undiluted state, ${ }^{8}$ those in solutions, and also $J_{\mathrm{e}}$ of star-shaped polymers in solutions, respectively, it is difficult to draw a clear conclusion from the respective series of data. If we observe all the data in Figures 6(A) and (B), and take into account the behavior of $J_{\mathrm{e}}$ of linear polymers in solution and melt, it is, at least qualitatively, clear that $J_{\mathrm{eR}}$ of comb-shaped polymers shows the same behavior as that of linear and star-shaped polymers. That is, $\log J_{\mathrm{eR}} v s . \log (C M)$ plot is horizontal in the Rouse region and show a slope of minus unity in the network region. The hump in the intermediate region of $\log J_{\mathrm{eR}} v s$. $\log$ $(C M)$ plot in Figure 6(A) may cause a confusion in our analysis if we analize the $J_{\mathrm{e}}$ data of combshaped polystyrenes in solutions only. Considering the polydispersity of these samples with respect to the degree of branching, however, it is not proper in our opinion to place too much emphasis on the hump in Figure 6(A).

Figure 6(B) shows that $J_{\mathrm{eR}}$ of four-armed, starshaped polymers, including the data in the undiluted state, form a horizontal line. In a recent paper, ${ }^{24}$ Graessley and Roovers dealt with $J_{\mathrm{e}}$ of star-shaped polystyrenes. They also did not find the network region for star-shaped polystyrenes. If the polymer concentration and molecular weight dependence of $J_{\mathrm{e}}$ of branched polymers is determined by the mechanism similar to the one in linear polymers, then the present star-shaped polymers even in the undiluted state are in the Rouse region, as was reported in the results section. That is, the fourarmed, star-shaped polymers in the present molecular weight range do not form a quasi-network 


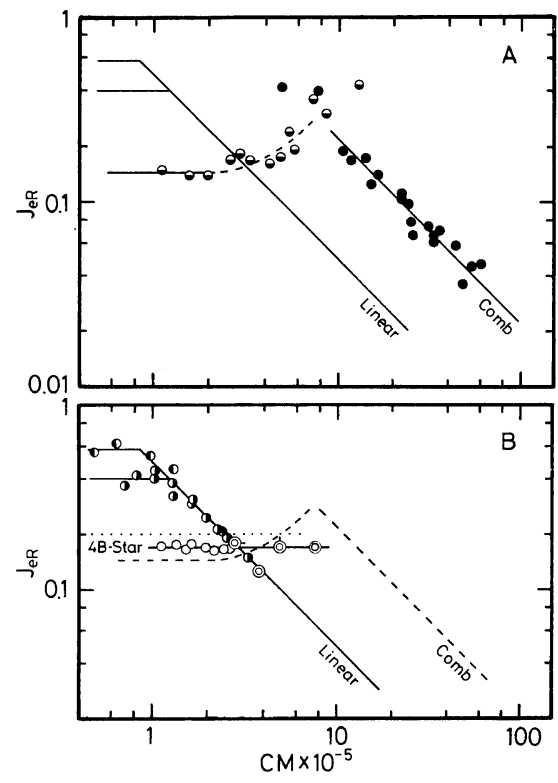

Figure 6. Double-logarithmic plots of $J_{\mathrm{eR}} v s$. CM. (A) Samples are comb-shaped polystyrenes. Symbols $\ominus$ and - show the data for comb-shaped polymers in DOP and at the undiluted state. ${ }^{8.9}$ Solid line "Linear" is the same as in Figure 6(B). (B) Samples are linear and four-armed, star-shaped polystyrenes. Symbols $\odot, \mathcal{D}$, and $\odot$ show the data for linear polystyrenes in $\alpha-\mathrm{CN}, \mathrm{DOP}$ and at the undiluted state, ${ }^{9}$ respectively. Open circles and double circles with pip show the data for four-armed, starshaped polystyrenes in $\alpha-\mathrm{CN}$ and at the undiluted state, ${ }^{1}$ respectively. The broken line "Comb" is the same as in Figure 6(A).

even in the undiluted state, as was pointed out in the preceding paper. ${ }^{1}$

Moreover, it is clear from Figures 6(A) and (B) that $\log J_{\mathrm{eR}}$ vs. $\log (C M)$ plot of branched polymers in the network region do not fit the line for the corresponding linear polymers, and this is in disagreement with the previous conclusion, ${ }^{25}$ where two lines for linear and three-armed, star-shaped poly $(\alpha$-methylstyrene)s agree with each other. If we carefully re-examined the data in the previous paper, ${ }^{25}$ it may be possible to draw the line so that the line for three-armed, star-shaped polymers is slightly above that for linear polymers. That is, the critical molecular weight for quasi-network formation is higher in branched polymers than in linear polymers. Therefore, if we compare $J_{\mathrm{e}}$ of branched polymers with that of linear polymers at the same value of $C M, J_{\mathrm{e}}$ of branched polymers is higher than that of linear polymers.

The increase in the critical value of $C M$, i.e., the enhancement in $J_{\mathrm{e}}$ by branching may be caused by the difference between the state of entanglement for linear polymers and that for branched polymers, as was previously pointed out by Fujimoto et al. ${ }^{8}$ That is, because of the small radius of gyration and the high segment density of branched polymers, the coil cannot overlap extensively but must interpenetrate each other only in the surface region of the polymer coil.

In the Rouse region, it was pointed out by Kajiura et $a .^{25}$ that, according to the theory of Zimm and Kilb, ${ }^{31}$ the ratio of $J_{\mathrm{eR}}$ of a star-shaped polymer to that of the corresponding linear polymer is expressed by the following equation,

$$
\left(J_{\mathrm{eR}}\right)_{\mathrm{b}} /\left(J_{\mathrm{eR}}\right)_{1}=g_{\mathrm{J}}
$$

where

$$
\begin{gathered}
g_{\mathrm{J}}=\{15(f-1)+1\} /\{3(f-1)+1\}^{2} \\
\text { (if draining) } \\
g_{\mathrm{J}}=\{31.8(f-1)+3.6\} /\{3.90(f-1)+1.96\}^{2} \\
\text { (if non-draining) }
\end{gathered}
$$

Equations 9-a and -b give almost an identical value. In the case of $f=4, g_{\mathrm{J}}=0.46$ and 0.53 , respectively. If the star-shaped polymers have many branches, eq 9-a and 9-b are approximated by

$$
\begin{array}{ll}
g_{\mathrm{J}}=1.67 /(f-1) & \text { (if draining) } \\
g_{\mathrm{J}}=2.09 /(f-1) & \text { (if non-draining) }
\end{array}
$$

Comparison of the experimental $J_{\mathrm{eR}}$ of the fourarmed polystyrenes with eq 8 and 9 is shown in Figure 6(B). The theoretical line calculated assuming $g_{\mathrm{J}}=0.50$ is shown by a dotted line. The agreement between theory and experiments is as satisfactory as that in a previous paper. ${ }^{25}$ However, $J_{\text {eR }}$ of highly branched, comb-shaped polymers in Figure 6(A) appear to be independent of the number of branches in the whole concentration range, which is in disagreement with the prediction of eq 10. A clearer comparison between theory and experiments is possible if we re-plot the experimental data in the following way. 
That is, in the Rouse region, $\left(J_{\mathrm{eR}}\right)_{\mathrm{b}} /\left\{\left(J_{\mathrm{eR}}\right)_{1} g_{\mathrm{J}}\right\}$ is unity irrespective of the number of branches if the theory of Zimm and Kilb ${ }^{31}$ is applicable. $\left(J_{\mathrm{eR}}\right)_{\mathrm{b}} /$ $\left\{\left(J_{\mathrm{eR}}\right)_{1} g_{\mathrm{J}}\right\}$ of four-armed, star-shaped polystyrenes having different molecular weights as well as that of highly branched, comb-shaped polystyrenes are double-logarithmically plotted against $C M$ in

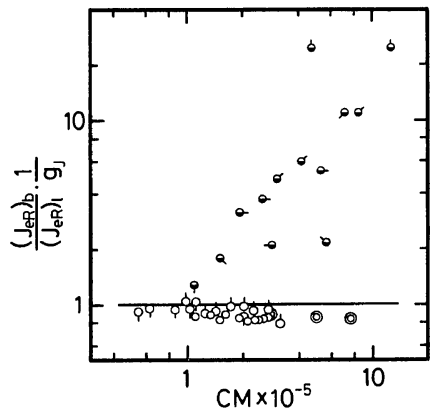

Figure 7. Double-logarithmic plot of $\left(J_{\mathrm{eR}}\right)_{\mathrm{b}} /\left\{\left(J_{\mathrm{eR}}\right)_{1} g_{\mathrm{J}}\right\}$ vs. $C M$. Samples are three-armed, star-shaped poly $(\alpha-$ methylstyrene)s and also four-armed, star-shaped, and comb-shaped polystyrenes. Symbols $\bigcirc$ and $\bigcirc$ show the data for three-armed, star-shaped poly $(\alpha-$ methylstyrene)s in $\alpha-\mathrm{CN}$ and undecylanisitate, respectively. As reported previously. ${ }^{25}$ Symbols $\bigcirc$ and $\odot$ show the data for four-armed, star-shaped polystyrenes in $\alpha$ $\mathrm{CN}$ and at the undiluted state, ${ }^{1}$ respectively. Symbol $\odot$ shows the data for comb-shaped polystyrenes in DOP. Various directions of pips of the symbol $\theta$ show the sample codes; succesive $45^{\circ}$ rotations clockwise from the upward direction correspond to $\mathrm{H}-2, \mathrm{H}-4, \mathrm{H}-5, \mathrm{H}-7, \mathrm{H}-$ $8, \mathrm{I}-2, \mathrm{I}-6$, and $\mathrm{J}-2$, respectively.

Figure 7, by assuming $g_{\mathrm{J}}=0.50$ and $1.88 /(f-1)$ for four-armed, star-shaped and comb-shaped polymers, respectively. In this figure, the data of three-armed, star-shaped poly $(\alpha$-methylstyrene)s reported previously ${ }^{25}$ are also plotted, by assuming $g_{\mathrm{J}}=0.67$. It is clear from Figure 7 that the data for three- and fourarmed polymers well agree with eq 8 . However, the data for comb-shaped polymers do not agree with eq 8 . These conclusions agree with the conclusions of Ferry et al. in dilute solutions. ${ }^{6,7,33}$

At present, we cannot explain why highly branched, comb-shaped polymers do not agree with the theory of Zimm and Kilb, ${ }^{31}$ despite the fact that these polymers are geometrically star-like. This may be either because the branches of these polymers are not connected to a common center or because Zimm and Kilb's assumption fails if the number of branches is (too) high.

\section{Zero-Shear Viscosity}

If the polymer chains are entangled enough, the ratio of the zero-shear viscosity of branched polymers $\left(\eta_{\mathrm{b}}{ }^{0}\right)$ to that of the corresponding linear polymer having the same molecular weight $\left(\eta_{1}{ }^{0}\right)$ at the same polymer concentration is given by ${ }^{27}$

$$
\eta_{\mathrm{b}}{ }^{0} / \eta_{1}{ }^{0}=g_{\mathrm{s}}{ }^{3.5}
$$

where $g_{\mathrm{s}}$ is given by eq 1 . But, this theory has been idealized too much, eq 11 is modified $^{8,25}$ as

$$
\eta_{\mathrm{b}}{ }^{0} / \eta_{1}{ }^{0}=5.67 g_{\mathrm{s}}(1 / f)^{2.5}
$$

taking into account the theory of Graessley. ${ }^{26}$ Both eq 11 and 12 imply that $\log \eta^{0}$ vs. $\log C$ plot for linear and branched polymers having the same molecular weight must be parallel. Figures 2 and 3 show that this prediction is correct for both fourarmed and highly-branched polystyrenes.

Moreover, both eq 11 and 12 predict that $\eta_{\mathrm{b}}{ }^{0} / \eta_{1}{ }^{0}$ should be independent of molecular weight and, therefore, $\eta_{\mathrm{b}}{ }^{0}$ should increase in the 3.4 th power in proportion to the molecular weight. In practice, however, it was reported ${ }^{8}$ that $\eta_{\mathrm{b}}{ }^{0}$ of comb-shaped polystyrenes increases in the $4.3 \mathrm{rd}$ power in proportion to the molecular weight, rather than in the 3.4th power. The data for four-armed polystyrenes in Figure 4 in this paper and Figure 6 in a previous paper ${ }^{1}$ also show that $\eta_{\mathrm{b}}{ }^{0}$ increases in the $4.3 \mathrm{rd}$ power in proportion to the molecular weight, in fairly good agreement with the results obtained by Masuda et al. ${ }^{17}$ Utracki et al.,${ }^{18}$ and Graessley et $a l{ }^{24}$ with four-armed, star-shaped polystyrenes. Thus, it may be concluded that linear and branched polystyrenes also have different slopes in the plot of $\log \eta^{0}$ vs. $\log M$, though the difference is not so marked as in the case of polybutadiene and others. ${ }^{19-23}$ Graessley et al. explained this phenomena with the reptation model in the branched tunnel $^{23,32}$ and recently with the third relaxation mechanism which is different from the first and the second mechanisms associated with intramolecular motion and the motion of the whole molecule, respectively. ${ }^{24}$

From the above fact, too, it may be certain that there is a difference in the state of entanglement 


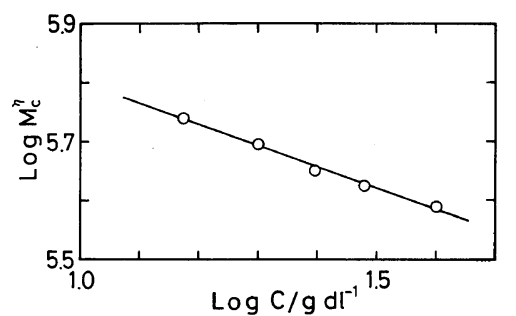

Figure 8. Concentration dependence of critical molecular weight $M_{\mathrm{c}}{ }^{\eta}$ for $\alpha$-CN solutions of four-armed, starshaped polystyrenes at $50^{\circ} \mathrm{C}$.

between linear and branched polymers. If the entanglement formation is sufficient in polymer solutions, the effect of an increment in polymer concentration on viscosity should be equivalent to that of an increment in molecular weight, so that the critical molecular weight $M_{\mathrm{c}}{ }^{\eta}$ in the $\eta^{0}$ vs. $M$ relationship should be proportional to the inverse concentration of polymer $C^{-1}$. The experimental data of linear polystyrenes agree with this prediction. ${ }^{5}$ However, the data of branched polymers in Figure 4 show that the critical molecular weight $M_{\mathrm{c}}{ }^{n}$ is not proportional to the inverse concentration of polymer $C^{-1}$, as shown in Figure 8 . The slope is only -0.36 .

Acknowledgement. This work was supported by a Grant-in-Aid for Scientific Research (Kagaku Kenkyu-hi, 147086-1976 and 1977) from the Ministry of Education, Science and Culture of Japan.

\section{REFERENCES}

1. Y. Isono, T. Fujimoto, H. Inagaki, M. Shishido, and M. Nagasawa, Polym. J., 12, 131 (1980).

2. T. Fujimoto, N. Ozaki, and M. Nagasawa, J. Polym. Sci., A-2, 6, 129 (1968).

3. M. Sakai, T. Fujimoto, and M. Nagasawa, Macromolecules, 5, 786 (1972).

4. J. D. Ferry, "Viscoelastic Properties of Polymers," 2nd ed, Wiley, New York, N.Y., 1970.
5. W. W. Graessley, Adv. Polym. Sci., 16, 1 (1974).

6. K. Osaki, Y. Mitsuda, R. M. Johnson, J. L. Schrag, and J. D. Ferry, Macromolecules, 5, 17 (1972).

7. Y. Mitsuda, K. Osaki, J. L. Schrag, and J. D. Ferry, Polym. J., 4, 24 (1973).

8. T. Fujimoto, H. Narukawa, and M. Nagasawa, Macromolecules, 3, 57 (1970).

9. T. Fujimoto, H. Kajiura, M. Hirose, and $M$. Nagasawa, Polym. J., 3, 181 (1972).

10. B. H. Zimm and W. H. Stockmayer, J. Chem. Phys., 17, 1301 (1949).

11. T. A. Oroffino, Polymer, 2, 305 (1961).

12. G. C. Berry and T. A. Oroffino, J. Chem. Phys., 40, 1614 (1964).

13. T. Fujimoto and M. Nagasawa, Polym. J., 7, 397 (1975).

14. G. C. Berry, J. Chem. Phys., 46, 1338 (1967).

15. H. Endo and M. Nagasawa, J. Polym. Sci., A-2, 8, 371 (1970).

16. H. Kajiura, H. Endo, and M. Nagasawa, J. Polym. Sci., Polym. Phys. Ed., 11, 2371 (1973).

17. T. Masuda, Y. Ohta, and S. Onogi, Macromolecules, 4, 763 (1971).

18. L. A. Utracki and J. E. L. Roovers, Macromolecules, 6, 366 (1973).

19. G. Kraus and J. T. Gruver, J. Polym. Sci., A, 3, 105 (1965).

20. G. Kraus and J. T. Gruver, J. Polym. Sci., Polym. Phys. Ed., 8, 305 (1970).

21. R. A. Mendelson, W. A. Bowles, and F. L. Finger, $J$. Polym. Sci., A-2, 8, 105 (1970).

22. R. P. Chartoff and B. Mazwell, J. Polym. Sci., A-2, 8, 455 (1970).

23. W. W. Graessley, T. Masuda, J. E. L. Roovers, and H. Hadjichristidis, Macromolecules, 9, 127 (1976).

24. W. W. Graessley and J. Roovers, Macromolecules, 12, 959 (1979).

25. H. Kajiura, Y. Ushiyama, T. Fujimoto, and M. Nagasawa, Macromolecules, 11, 894 (1978).

26. W. W. Graessley, J. Chem. Phys., 43, 2696 (1965); 47, 1942 (1967); 54, 5143 (1971).

27. F. Bueche, J. Chem. Phys., 40, 484 (1964).

28. P. E. Rouse, J. Chem. Phys., 21, 1272 (1953).

29. F. Bueche, J. Chem. Phys., 22, 603 (1954).

30. B. H. Zimm, J. Chem. Phys., 24, 269 (1956).

31. B. H. Zimm and R. W. Kilb., J. Polym. Sci., 37, 19 (1959).

32. W. W. Graessley, Acc. Chem. Res., 10, 332 (1977).

33. Y. Mitsuda, J. L. Schrag, and J. D. Ferry, Polym. J., 4, 668 (1973). 